Article

\title{
An Interleaved DC/DC Converter with Soft-switching Characteristic and high Step-up Ratio
}

\author{
Yong-Nong Chang ${ }^{1}\left(\mathbb{D}\right.$, Hung-Liang Cheng ${ }^{2, *} \mathbb{C}$, Hau-Chen Yen ${ }^{3}$, Chien-Hsuan Chang ${ }^{2} \mathbb{C}$ and \\ Wei-Di Huang ${ }^{2}$ \\ 1 Department of Electrical Engineering, National Formosa University, Hu-Wei, Yunlin 63201, Taiwan; \\ ynchang@nfu.edu.tw \\ 2 Department of Electrical Engineering, I-Shou University, Kaohsiung 84001, Taiwan; \\ chchang@isu.edu.tw (C.-H.C.); relax592@gmail.com (W.-D.H.) \\ 3 Department Electrical Engineering, Far East University, Tainan 74448, Taiwan; yenc66@mail.feu.edu.tw \\ * Correspondence: hlcheng@isu.edu.tw; Tel.: +886-7-657-7711 (ext. 6634)
}

Received: 25 February 2020; Accepted: 19 March 2020; Published: 22 March 2020

check for updates

\begin{abstract}
This study presents a dc/dc converter featuring soft-switching characteristic, high conversion efficiency, and high step-up ratio. The proposed circuit is composed of two parallel-connected boost converters. Only one coupled inductor is used to replace inductors of the boost converters which are interleaved operated at discontinuous-conduction mode (DCM). The current ripples at the input and the output terminals are reduced due to the interleaved operation. By freewheeling the current of the coupled inductor to discharge the stored electric charges in the parasitic capacitors of the active switches, both active switches can fulfill zero-voltage switching on (ZVS). Owing to DCM operation, the freewheeling diodes can fulfill zero-current switching off (ZCS). Therefore, the power conversion efficiency is improved. The operation principle for each operation mode is analyzed in detail and design equations for the component parameters are provided in this report. Finally, a prototype $200 \mathrm{~W} 48-400 \mathrm{~V}$ converter was implemented and measured to demonstrate the effectiveness of the proposed circuit.
\end{abstract}

Keywords: boost converter; discontinuous-conduction mode (DCM); interleaved operation; voltage gain; zero-current switching off (ZCS); zero-voltage switching on (ZVS)

\section{Introduction}

Recently, renewable energies have been increasingly used to meet growing energy demands and mitigate climate change caused by the greenhouse effect due to the burning of large amounts of fossil fuels. Batteries are often used in energy storage systems to compensate the power fluctuation between renewable power generation systems and consumption [1-3]. Since battery voltage is usually small and has a wide range of variation, a high step-up dc/dc converter is indispensable on application where high dc voltage is required [4-6]. The boost converter has been widely adopted for step-up application because it has the advantages of simple circuit architecture and easy control $[7,8]$. Theoretically, the voltage gain of a boost converter is tremendous high when its duty ratio is close to 1 . Under ideal conditions, the value of the voltage gain at the 0.9 duty cycle is equal to 10 . Nevertheless, it is impractical to operate a boost converter at such a high duty cycle, because when the resistance of the inductor and the semiconductor device is considered in the actual circuit, both the circuit efficiency and the voltage gain will be greatly reduced [9]. On the other hand, the voltage gain of a boost converter operating at discontinuous-conduction mode (DCM) is higher than that of a boost converter operating at continuous-conduction mode (CCM). A DCM operated boost converter could provide a reasonable solution for achieving high voltage gain. Nevertheless, a smaller inductor is used at DCM operation 
and the current ripples at both the input and the output sides are high. It requires a large capacitor to filter out the current ripple to obtain a smooth output voltage.

The circuit efficiency is another important issue for direct current-to-direct current (DC/DC) converters. However, the traditional pulse-width modulation (PWM) converters operate at hard switching, leading to high switching losses and high voltage and/or current stresses. In order to solve the drawbacks of hard switching, researchers have proposed many soft-switching technologies to enable the semiconductor devices operate at either ZVS or ZCS. Synchronous rectification (SR) technique is popularly applied to reduce the conduction loss, especially when the output is low voltage and high current. SR technique use a synchronous switch to replace the freewheel diode. If the synchronous switch remains on until the inductor current decreases from positive to negative, the active switch can achieve ZVS operation by flowing the negative current of the inductor to release to charge stored in its parasitic capacitor [10-12]. However, the SR technique is more complicated since it requires a current sensor and corresponding control to precisely turn off the synchronous switch. The active clamping circuits or snubber circuits are often used to achieve soft-switching operation [13-16]. However, these techniques need to use additional auxiliary active switches, diodes, and/or passive components to operate the main active switch at ZVS. The control circuit is more complicated and circuit cost is higher. Besides, the current loops in the active clamping or snubber circuits would cause conduction losses and even more switching losses.

In addition to increasing power capacity and reducing current ripple, some interleaved $\mathrm{dc} / \mathrm{dc}$ converters also have the advantages of ZVS operation [17-20]. In these interleaved converters, the active switches are arranged to be turned on and off alternately and an additional inductor is added. The principle of ZVS operation is similar to that of SR technology. The additional inductor is operated at CCM. As soon as one active switch is turned off, the current of the additional inductor will flow through the parasitic capacitor of the other active switch to release its stored energy. When the parasitic capacitor is fully discharged, the diode connected in parallel with the active switch conducts to clamp the active switch at near zero volts. Then, it can be turned on at zero voltage. Unfortunately, the added inductor is usually larger than the energy-stored inductor of the PWM-typed converter. It hinders reducing the size and improving the efficiency of the converter.

Aiming to solve the above shortcomings and propose a better solution, this manuscript presents an interleaved converter. It is mainly composed of two boost converters connected in parallel. A coupled inductor consisting of a magnetic core and two windings is used instead of the two inductors of the boost converters. Although the boost converters are designed to operate at DCM, the current ripple is low due to interleaved operation. High circuit efficiency is achieved by operating all the semiconductors at either ZVS or ZCS. A $200 \mathrm{~W} 48 \mathrm{~V} / 400 \mathrm{~V}$ prototype converter is built and measured to verify the feasibility of this proposed circuit.

\section{Proposed Circuit Configuration and Operation Analysis}

\subsection{Proposed Circuit Configuration}

Figure 1 shows the proposed interleaved dc/dc converter. It is mainly composed of two boost converters where the coupled inductor $\left(T_{1}\right)$ served as the energy-stored inductor. The coupled inductor is made up of a magnetic core and two windings with the same number of turns. Two MOSFETs $\left(S_{1}, S_{2}\right)$ play the role of active switches. Two diodes $\left(D_{1}, D_{2}\right)$ are used to freewheel the inductor current while the other two diodes $\left(D_{S_{1}}, D_{S_{2}}\right)$ respectively in parallel with $S_{1}$ and $S_{2}$ are the intrinsic diodes of the MOSFETs. The gate-source voltages $\left(v_{G S 1}, v_{G S 2}\right)$ are used to alternatively turn the active switches on and off at a high switching frequency $f_{s}$. The waveforms of $v_{G S 1}$ and $v_{G S 2}$ are shown in Figure 2 . They are complementary rectangular waveforms with a short overlap time between them. 


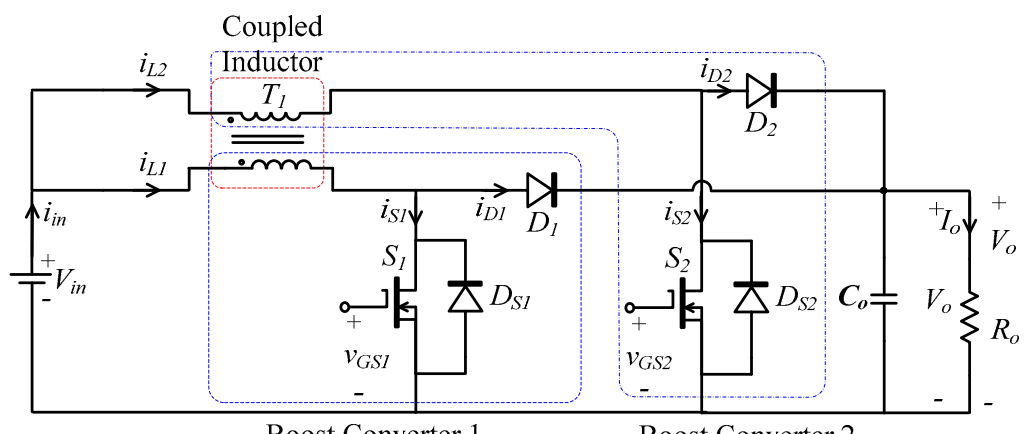

Boost Converter $1 \quad$ Boost Converter 2

Figure 1. Proposed interleaved dc-to-dc converter.

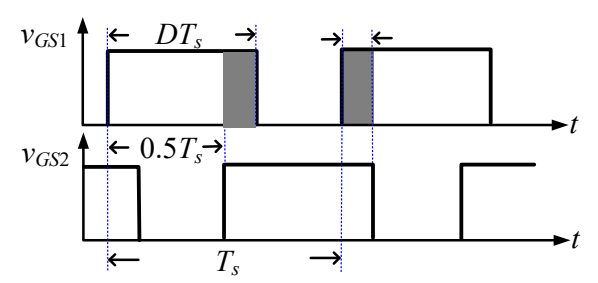

Figure 2. Gate-source voltages $v_{G S 1}$ and $v_{G S 2}$.

Ignoring the winding resistance and the core loss, the equivalent circuit of the coupled inductor is shown in Figure 3. $T_{M}$ is a transformer with a turn ratio equal to 1 , and $L_{M}$ is its mutual inductance. $L_{1}$ and $L_{2}$ represent the leakage inductances in the primary winding and the secondary ones, respectively. Based on the equivalent circuit, the currents flowing into $L_{1}$ and $L_{2}$, denoted by $i_{L 1}$ and $i_{L 2}$ can be expressed as

$$
\begin{aligned}
& i_{L 1}=i_{L M}+i_{T 1}, \\
& i_{L 2}=i_{T 2}=-i_{T 1},
\end{aligned}
$$

where $i_{T 1}, i_{T 2}$, and $i_{L M}$ are the primary current, the secondary current and the magnetic exciting current of the transformer, respectively. From Figure 1 , the input current denoted by $i_{\text {in }}$ would be equal the sum of $i_{L 1}$ and $i_{L 2}$. Based on Equations (1) and (2), $i_{i n}$ is equal to the magnetic exciting current.

$$
i_{\text {in }}=i_{L 1}+i_{L 2}=i_{L M}
$$

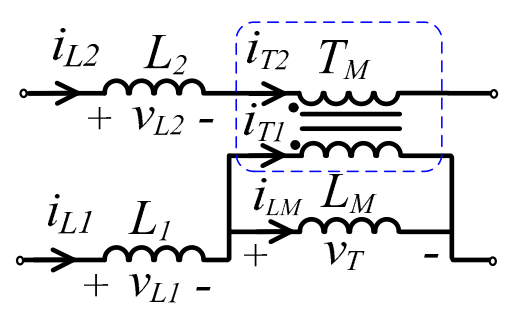

Figure 3. Equivalent circuit for the coupled inductor.

The voltages across both windings of the transformer are equal and can be expressed as:

$$
v_{T}=\frac{L_{M} d i_{L M}}{d t},
$$




\subsection{Circuir Analysis}

In order to simplify the circuit analysis, some assumptions are made as follows.

- The semiconductor devices are ideal in spite of considering the intrinsic diode and the parasitic capacitance of the MOSFETs.

- The leakage inductances are equal $\left(L_{1}=L_{2}=L_{l}\right)$. The mutual inductance $L_{M}$ is large enough and the magnetic exciting current $i_{L M}$ is constant.

- The output capacitance $C_{o}$ is large enough. Hence, the output voltage $V_{o}$ is regarded as constant.

Accorrding the conducting status of the semiconductor devices, there are eigth operation modes in one high-frequency cycle at steady-state operation. Figure 4 shows the current loops for each operation mode and Figure 5 illustrates the conceptual voltage and current waveforms of the main components.

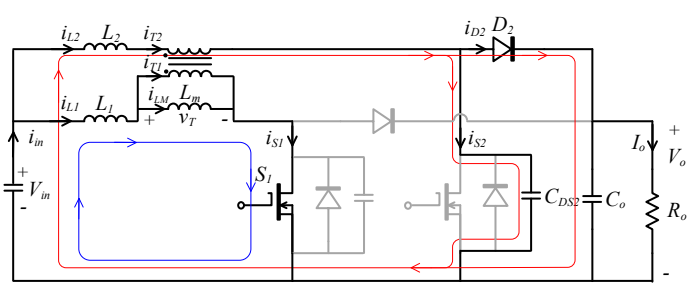

(a) Mode I

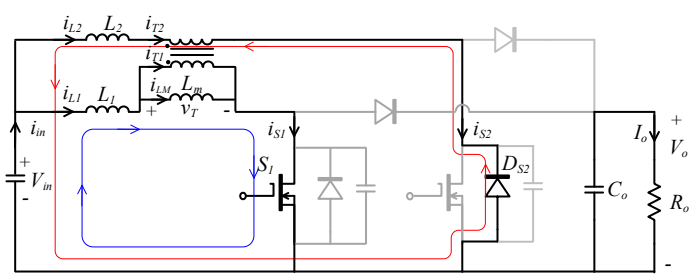

(c) Mode III

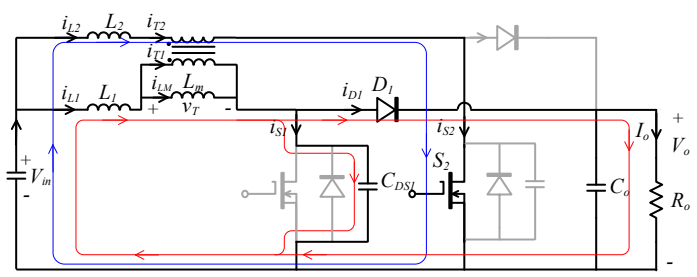

(e) Mode V

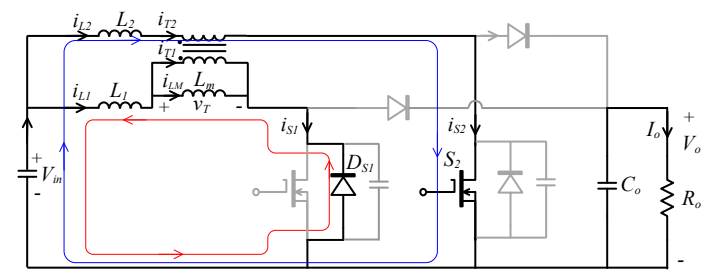

(g) Mode VII

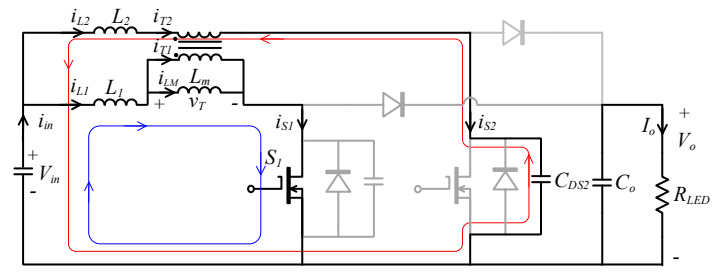

(b) Mode II

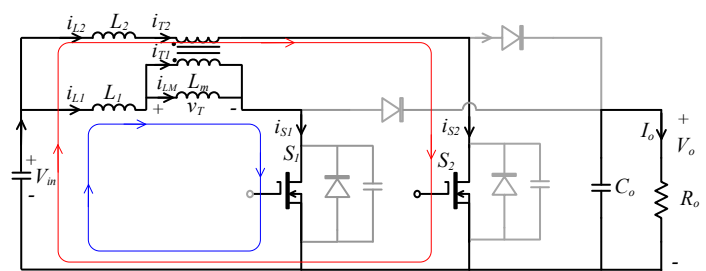

(d) Mode IV

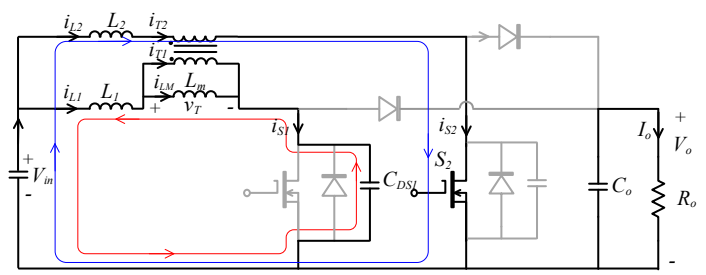

(f) Mode VI

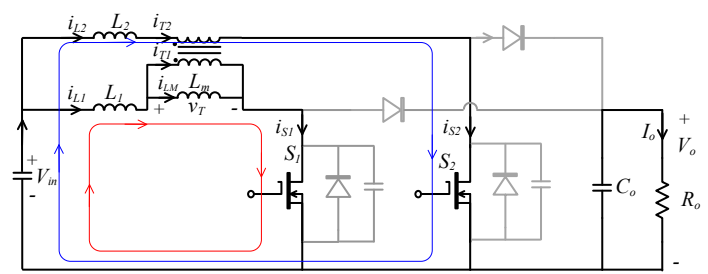

(h) Mode VIII

Figure 4. Operation modes. 


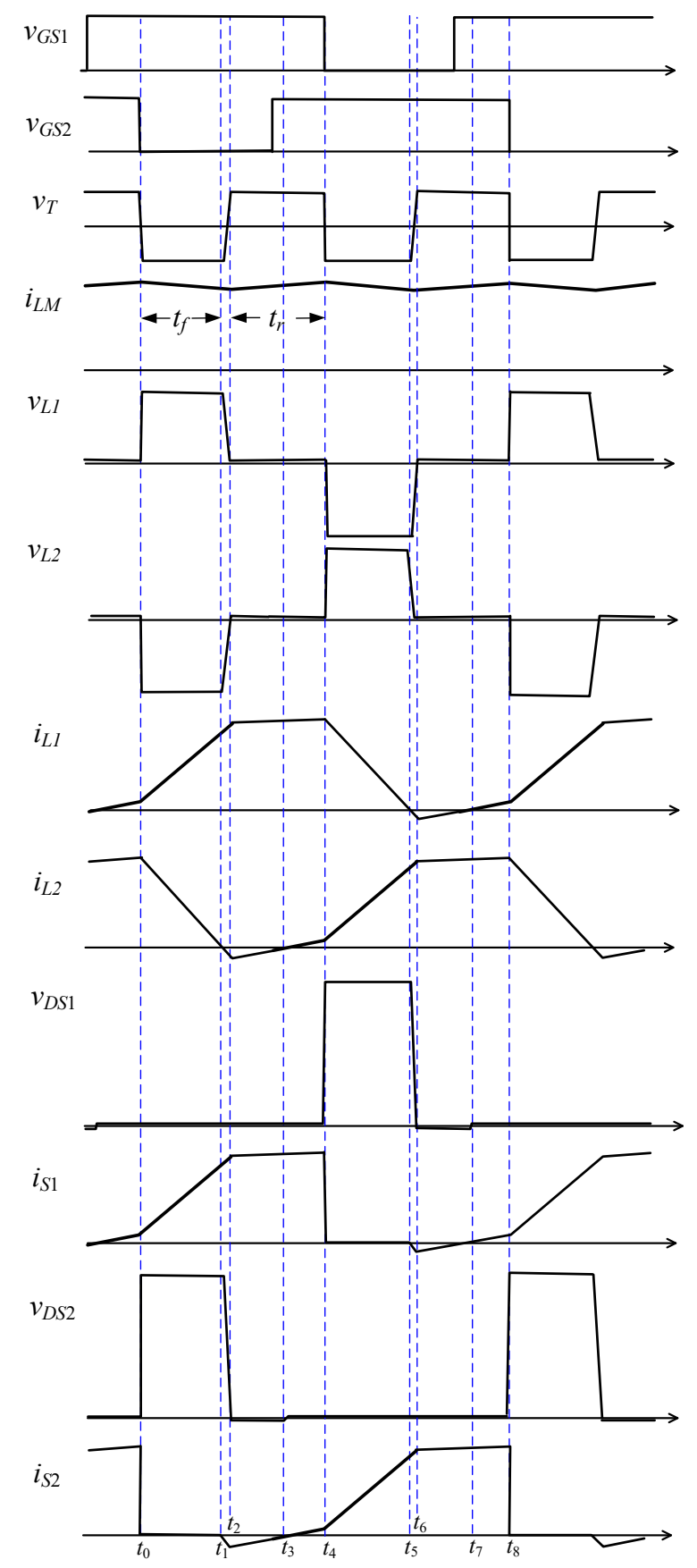

Figure 5. Conceptual waveforms.

A. Mode I $\left(t_{0}<t<t_{1}\right)$

Before the beginning of Mode I, both active switches $S_{1}$ and $S_{2}$ are on. There are two current loops. One is $i_{L 1}$ flows through $S_{1}$. The other is $i_{L 2}$ flows through $S_{2}$. Since $S_{2}$ is turned on before $S_{1}$, most of the magnetic exciting $i_{L M}$ are supplied by $i_{L 2}$.

Mode I starts at the instant when $v_{G S 2}$ drops to zero volts to turn off $S_{2}$. The equivalent circuit is shown in Figure $4 \mathrm{a}$. The current in the secondary winding $i_{L 2}$ diverts from $S_{2}$ to flow into its parasitic capacitance $C_{D S 2}$. Since the parasitic capacitance is generally very small, it takes a very short time for the voltage across $C_{D S 2}$ being charged to equal the output voltage $V_{o}$. Thereafter, $i_{L 2}$ diverts from 
$C_{D S 2}$ to flow through $D_{2}$ and the output capacitance $C_{o}$. During this period, $C_{o}$ is charged. The voltage equations of the two converters are as follows.

$$
\begin{gathered}
V_{\text {in }}=v_{L 1}+v_{T}, \\
V_{\text {in }}=v_{L 2}+v_{T}+v_{D S 2}=v_{L 2}+v_{T}+V_{o},
\end{gathered}
$$

where $v_{L 1}$ and $v_{L 2}$ represent the voltages across the leakage inductances $L_{1}$ and $L_{2}$, respectively. Adding Equations (5) and (6) gives

$$
2 V_{\text {in }}=\left(v_{L 1}+v_{L 2}\right)+2 v_{T}+V_{o}
$$

From Equation (3), the following equation is obtained.

$$
v_{L 1}+v_{L 2}=\frac{L_{l} d i_{L 1}}{d t}+\frac{L_{l} d i_{L 2}}{d t}=\frac{L_{l} d i_{L M}}{d t},
$$

The voltage across the mutual inductance can be obtained by substituting Equations (4) and (8) into Equation (7).

$$
v_{T}=\frac{L_{M}}{L_{l}+2 L_{M}}\left(2 V_{\text {in }}-V_{o}\right),
$$

By designing $V_{o}$ to be higher than two times of $V_{i n}, v_{T}$ would be negative and $i_{L M}$ would decrease linearly in this mode. The voltages across the leakage inductances can be expressed as Equations (10) and (11) by substituting Equation (9) into Equations (5) and (6), respectively.

$$
\begin{gathered}
v_{L 1}=\frac{L_{l} V_{\text {in }}}{L_{l}+2 L_{M}}+\frac{L_{M} V_{o}}{L_{l}+2 L_{M}}, \\
v_{L 2}=\frac{L_{l} V_{\text {in }}}{L_{l}+2 L_{M}}-\frac{\left(L_{l}+L_{M}\right) V_{o}}{L_{l}+2 L_{M}},
\end{gathered}
$$

From Equations (10) and (11), $v_{L 1}$ is positive and $v_{L 2}$ is negative since $L_{m}$ is much larger than $L_{l}$. Hence, $i_{L 1}$ rises and $i_{L 2}$ decreases linearly. It means that the magnetic exciting current diverts form the secondary winding to the primary winding. As soon as $i_{L 2}$ decreases to zero, $D_{2}$ turns off and the circuit operation enters Mode II.

B. Mode II $\left(t_{1}<t<t_{2}\right)$

This mode describes the short transient for the $C_{D S 2}$ discharging from $V_{o}$ to $-0.7 \mathrm{~V}$. The equivalent circuit is shown in Figure $4 \mathrm{~b}$. During this mode, the voltage across $L_{2}$ can be expressed as

$$
v_{L 2}=V_{i n}-v_{T}-v_{D S 2},
$$

The voltage $v_{L 2}$ is negative and $i_{L 2}$ continuously decreases from zero. In other words, $i_{L 2}$ changes polarity and becomes negative. The current loop of $i_{L 2}$ is $C_{D S 2}$, the secondary winding, $V_{i n}$. The voltages $v_{L 1}, v_{L 2}$ and $v_{T}$ are expressed as

$$
\begin{gathered}
v_{L 1}=\frac{L_{l} V_{i n}}{L_{l}+2 L_{M}}+\frac{L_{M} v_{D S 2}}{L_{l}+2 L_{M}}, \\
v_{L 2}=\frac{L_{l} V_{i n}}{L_{l}+2 L_{M}}-\frac{\left(L_{l}+L_{M}\right) v_{D S 2}}{L_{l}+2 L_{M}}, \\
v_{T}=\frac{L_{M}}{L_{l}+2 L_{M}}\left(2 V_{\text {in }}-v_{D S 2}\right),
\end{gathered}
$$


During this mode, $C_{D S 2}$ is discharged and $v_{D S 2}$ keeps decreasing. From Equations(13) - (15), $v_{L 1}$ decreases. On the contrary, $v_{L 2}$ and $v_{T}$ both increase. As soon as $v_{D S 2}$ decreases to $-0.7 \mathrm{~V}, i_{L 2}$ diverts from $C_{D S 2}$ to $D_{S 2}$ and Mode II ends.

C. Mode III $\left(t_{2}<t<t_{3}\right)$

The equivalent circuit of Mode III is shown in Figure 4c. Neglecting the diode conduction voltage $(0.7 \mathrm{~V})$, the voltage equations for both converters are

$$
\begin{aligned}
& V_{\text {in }}=v_{L 1}+v_{T}, \\
& V_{\text {in }}=v_{L 2}+v_{T},
\end{aligned}
$$

Adding Equation (16) and Equation (17) results in

$$
2 V_{\text {in }}=\left(v_{L 1}+v_{L 2}\right)+2 v_{T},
$$

Substituting Equations (4) and (8) into Equation (18) leads to

$$
v_{T}=\frac{2 L_{M} V_{i n}}{L_{l}+2 L_{M}}
$$

Substituting Equation (19) into Equations (16) and (17) results in

$$
v_{L 1}=v_{L 2}=\frac{L_{l} V_{i n}}{L_{l}+2 L_{M}}
$$

From Equations (19) and (20), $v_{T}, v_{L 1}$, and $v_{L 2}$ are all positive. Since the mutual inductance $L_{M}$ is usually much higher than the leakage inductance $L_{l}$, the $v_{L 1}$ and $v_{L 2}$ are very small and the currents $i_{L 1}$ and $i_{L 2}$ rises slowly.

During this mode, $D_{S 2}$ is on and the drain to source voltage of $S_{2}$ is clamped at $0.7 \mathrm{~V}$. The gated voltage $v_{G S 2}$ becomes high level before $i_{L 2}$ rises to zero. When $i_{L 2}$ rises to zero and then becomes positive, $S_{2}$ is turned on at ZVS and Mode III ends.

D. Mode IV $\left(t_{3}<t<t_{4}\right)$

The voltage equations for $v_{T}, v_{L 1}$, and $v_{L 2}$ are as same as that of Mode III. The voltages $v_{T}, v_{L 1}$, and $v_{L 2}$ are all positive. Therefore, the currents $i_{L M}, i_{L 1}$, and $i_{L 2}$ keep rising. When the gated voltage $v_{G S 1}$ becomes zero volts. $S_{1}$ is turned off and the circuit enters Mode V.

E. Mode V $\left(t_{4}<t<t 5_{4}\right)$ - H. Mode VIII $\left(t_{7}<t<t_{8}\right)$

The equivalent circuits of Mode V to Mode VIII are shown in Figure 4e- $h$, respectively. Owing to the symmetrical operation for both boost converters, the operation of Mode V - Mode VIII is similar to the operation of Mode I- Mode IV. As soon as $v_{G S 2}$ drops zero, $S_{2}$ is turned off and Mode VIII ends. The circuit goes to the first mode of the next high frequency cycle.

\section{Design Equations}

Since the mutual inductance $L_{M}$ is large enough, $I_{L M}$ is assumed to be constant. Based on the principle of energy conservation, the output power is equal to

$$
P_{o}=\eta \times V_{\text {in }} \times I_{\text {in }}=\eta \times V_{\text {in }} \times I_{L M},
$$

where $\eta$ represents the circuit conversion efficiency. From (21), $I_{L M}$ can be expressed as

$$
I_{L M}=\frac{P_{o}}{\eta V_{\text {in }}}=\frac{V_{o}{ }^{2}}{\eta V_{\text {in }} R_{o}},
$$


By assuming that the mutual inductance $L_{M}$ is much larger than the leakage inductance $L_{l}$, from Equations (9)-(11), $v_{T}, v_{L 1}$, and $v_{L 2}$ in Mode I are approximately equal to

$$
\begin{gathered}
v_{T}=V_{\text {in }}-\left(\frac{V_{o}}{2}\right), \\
v_{L 1}=\frac{V_{o}}{2}, \\
v_{L 2}=\frac{-V_{o}}{2},
\end{gathered}
$$

In practical circuits, parasitic capacitors are very small. It takes only a short time to fully discharge the parasitic capacitor. It means that the period of Mode II is very short and hence $i_{L 2}$ is near zero at the end of this mode. Based on Equation (3), the peak value of $i_{L 2}$ is approximately equal to $I_{L M}$. In Mode $\mathrm{I}, i_{\mathrm{L} 2}$ decreases and the time required for the current $i_{\mathrm{L} 2}$ to drop from its maximum value to zero is equal to

$$
t_{f}=\frac{L_{l} I_{L M}}{v_{L 1}}=\frac{L_{l} I_{L M}}{V_{o} / 2}=\frac{2 L_{l} I_{L M}}{V_{o}}
$$

The voltage equations for $v_{T}$ in Mode I and in Mode III and Mode IV are Equations (9) and (19), respectively. At steady state, its average value should be zero.

$$
\overline{v_{T}}=\frac{L_{M}}{L_{l}+2 L_{M}}\left(2 V_{i n}-V_{o}\right) \cdot t_{f}+\frac{2 L_{M} V_{i n}}{L_{l}+2 L_{M}} \cdot t_{r}=0,
$$

where $t_{f}$ is the period of Mode I and $t_{r}$ is that of Mode III plus Mode IV. The fall time $t_{f}$ plus the rise time $t_{r}$ equals to half of the switching period

$$
t_{f}+t_{r}=0.5 T_{s}
$$

where $T_{S}$ represents the switching period. Combining Equations (27) and (28) gets

$$
t_{f}=\frac{V_{\text {in }}}{V_{o}} T_{s}
$$

Substituting Equation (29) into Equation (26) gets

$$
\frac{V_{\text {in }}}{V_{o}} T_{s}=\frac{2 I_{L M} L_{l}}{V_{o}},
$$

Combining Equations (22) and (30), the leakage inductance is obtained as

$$
L_{l}=\frac{V_{i n} T_{s}}{2 I_{L M}}=\frac{\eta V_{i n}^{2}}{2 P_{o} f_{s}}
$$

\section{Illustrative Example and Experimental Results}

A $200 \mathrm{~W}$ prototype was built and tested to verify the feasibility of the proposed circuit. The circuit specification is shown in Table 1 and the values of the circuit component are shown in Table 2. The input and output voltages are $48 \mathrm{~V}_{\mathrm{dc}}$ and $400 \mathrm{~V}_{\mathrm{dc}}$, respectively. The switching frequency of $50 \mathrm{kHz}$ is chosen. From Equation (31), the output power is inverse proportional to leakage inductance $L_{l}$. Assuming a circuit efficiency of $95 \%, L_{l}$ can be obtained.

$$
L_{l}=\frac{\eta V_{\text {in }}^{2} R_{o}}{2 V_{o}^{2} f_{s}}=\frac{0.95 \times 48^{2}}{2 \times 200 \times 50 \times 10^{3}}=0.11 \mathrm{mH}
$$


Table 1. Specification of the proposed converter.

\begin{tabular}{cc}
\hline Input voltage $V_{\text {in }}$ & $48 \mathrm{~V}_{\mathrm{dc}}$ \\
Output voltage $V_{o}$ & $400 \mathrm{~V}_{\mathrm{dc}}$ \\
Output current $I_{O}$ & $0.5 \mathrm{~A}$ \\
Load Resistance $R_{o}$ & $800 \Omega$ \\
Switching frequency $f_{s}$ & $50 \mathrm{kHz}$ \\
\hline
\end{tabular}

Table 2. Component parameters.

\begin{tabular}{cc}
\hline Leakage inductance $L_{1}, L_{2}$ & $0.11 \mathrm{mH}$ \\
Mutual inductance $L_{M}$ & $0.58 \mathrm{mH}$ \\
Output capacitance $C_{0}$ & $220 \mu \mathrm{F}$ \\
Diodes $D_{1}, D_{2}$ & C3D10060A \\
Active switches $S_{1}, S_{2}$ & 35N65M5 \\
\hline
\end{tabular}

The control circuit is illustrated in Figure 6. It includes a half-bridge self-oscillating driver (IR2153), two inverters (74LS04P) and two power metal-oxide-semiconductor field-effect transistor (MOSFET) gate drivers (TLP250). The IR2153 provides two complementary square voltages with dead time between them. After being inverted by 74LS04P, the output becomes two square voltages with overlapping times. Finally, the overlapping voltages are sent to the TLP250 and their outputs are used to drive the MOSFETs.

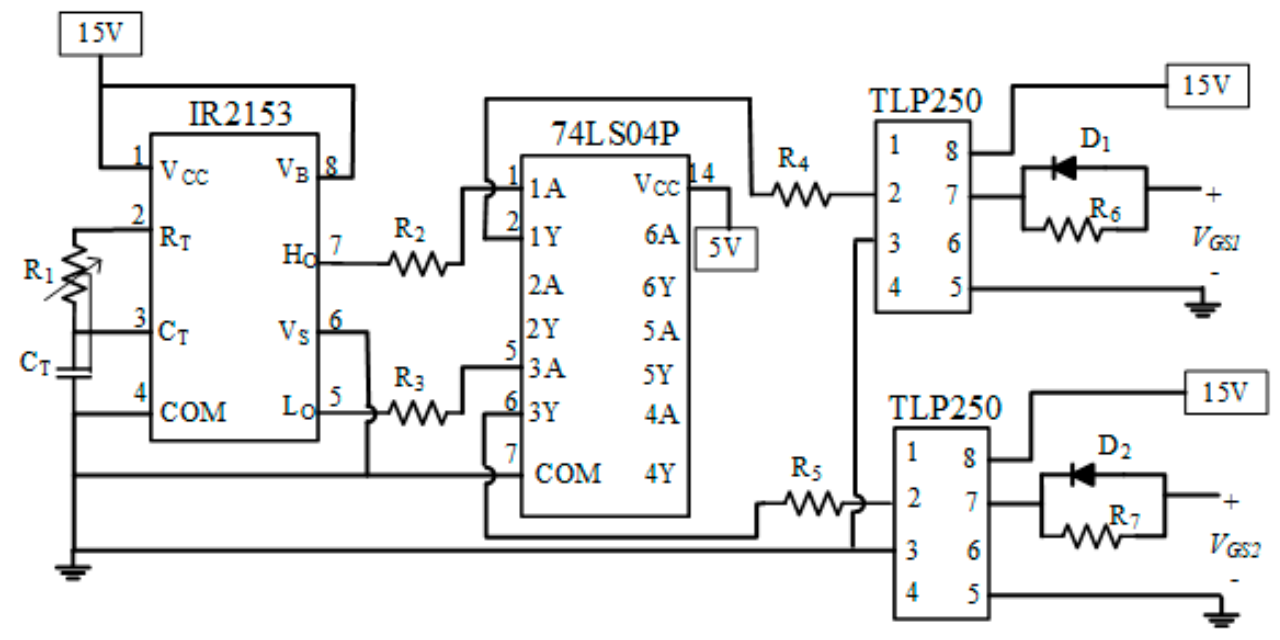

Figure 6. Control circuit.

The waveforms of the gate voltages, $v_{D S 1}$ and $v_{D S 2}$ are shown in Figure 7. As shown, there are overlapping time between them. Figure 8 shows the current waveforms in the primary and the secondary windings of the coupled inductor. As expected, both currents decrease from the peak value to a negative value near zero. The current and voltage waveforms of the active switches are shown in Figure 9. It demonstrates that both active switches are operated at ZVS. The drain-to-source voltages of $S_{1}$ and $S_{2}$ are clamped at $0.7 \mathrm{~V}$ when the current is negative. It is believed that the negative currents flow through the intrinsic diodes of $S_{1}$ and $S_{2}$. The output voltage and output current are shown in Figure 10. The measured voltage and current are $400 \mathrm{~V}$ and $0.5 \mathrm{~A}$, consistent with the theoretical prediction. The measured circuit efficiency is $94.3 \%$. 


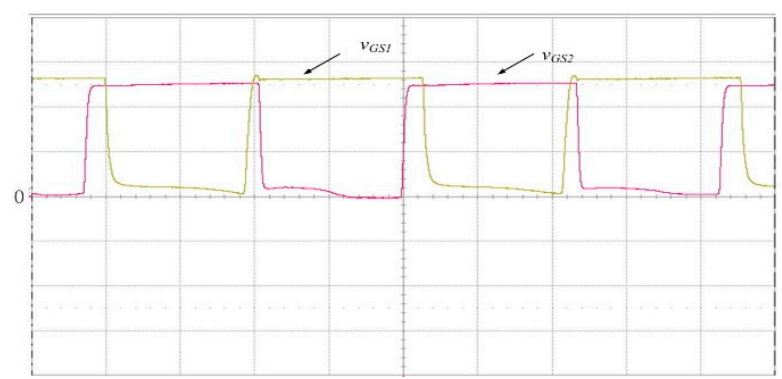

Figure 7. Voltage waveforms of $v_{D S 1}$ and $v_{D S 2} \cdot\left(v_{D S 1}, v_{D S 12}: 5 \mathrm{~V} / \mathrm{div}\right.$, time: $\left.5 \mu \mathrm{s} / \mathrm{div}\right)$

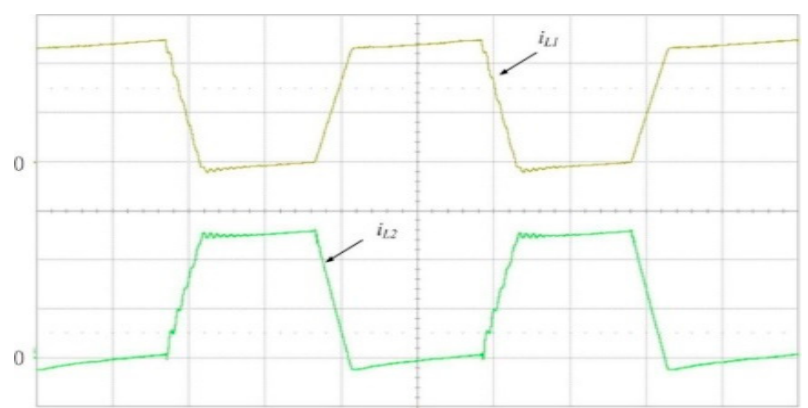

Figure 8. Current waveforms of $i_{L 1}$ and $i_{L 2} \cdot\left(i_{L 1}, i_{L 2}: 2 \mathrm{~A} / \mathrm{div}\right.$, time: $\left.5 \mu \mathrm{s} / \mathrm{div}\right)$

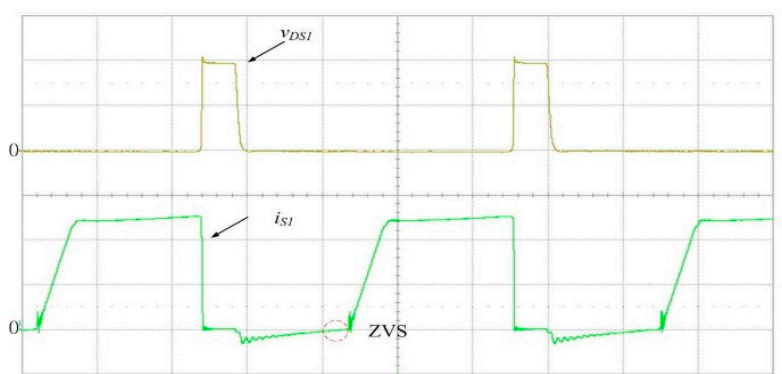

(a)

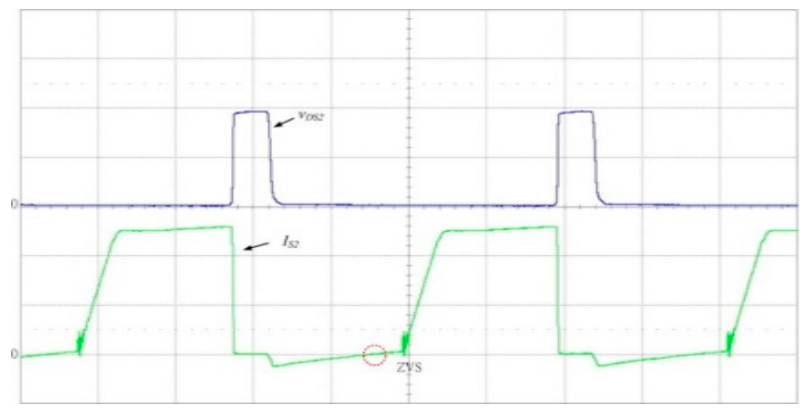

(b)

Figure 9. Voltage and current waveforms $(\mathbf{a}) v_{D S 1}$ and $i_{S 1}$, and (b) $v_{D S 2}$ and $i_{S 2} .\left(v_{D S 1}, v_{D S 2}: 200 \mathrm{~V} / \mathrm{div}\right.$, $i_{S 1}, i_{S 2}: 2 \mathrm{~A} /$ div, time: $5 \mu \mathrm{s} /$ div) 


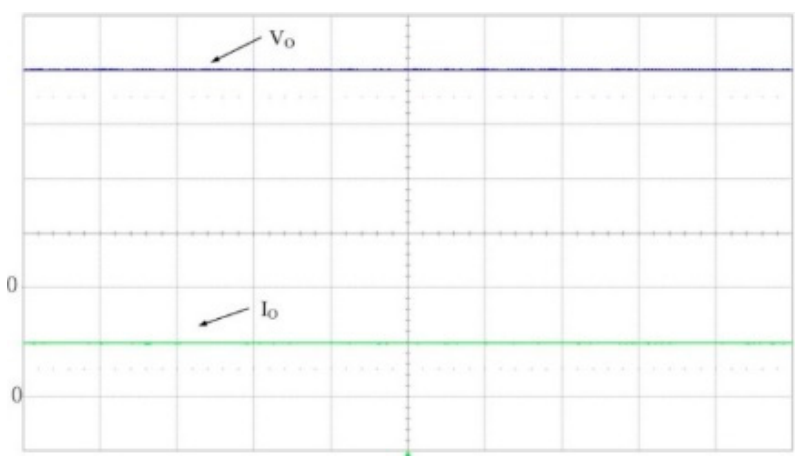

Figure 10. Waveform of $V_{o}$ and $I_{o} .\left(V_{o}: 100 \mathrm{~V} / \mathrm{div}, I_{o}: 0.5 \mathrm{~A} / \mathrm{div}\right.$, time: $\left.5 \mathrm{~ms} / \mathrm{div}\right)$

\section{Conclusions}

This paper proposes an interleaved $\mathrm{dc} / \mathrm{dc}$ converter that is composed of two boost converters. Both boost converters share a coupled inductor that is made up of one magnetic core with two windings. It effectively reduces the product size and cost. Owing to the interleaved operation, the power capacity is doubled. Moreover, low current ripple at both the input and the output sides is achieved due to the interleaved operation. By operating the boost converters at DCM, the freewheeling diodes and the active switches can respectively fulfill ZCS operation and ZVS operation, without the need to use any active clamping or snubber circuits. It helps to reduce the component count and improve the circuit efficiency. In summary, the proposed interleaved converter has the advantages of less component count, low current ripple, high circuit efficiency, and easy control. A $200 \mathrm{~W}$ prototype converter was implemented and measured. The circuit efficiency is $94.3 \%$ at rated power operation.

Author Contributions: Y.-N.C. and H.-L.C. conceived and designed the circuit; C.-H.C. and H.-C.Y. performed circuit simulations and designed parameters of the circuit components; W.-D.H. carried out the prototype converter, and measured as well as analyzed experimental results; H.-L.C. wrote the paper and Y.-N.C. revised it for submission. All authors have read and agreed to the published version of the manuscript.

Funding: This research received no external funding.

Acknowledgments: This work was supported by the Ministry of Science and Technology, R.O.C. under Grant MOST 105-2221-E-214-027.

Conflicts of Interest: The authors declare no conflicts of interest.

\section{References}

1. Yu, W.; Qian, H.; Lai, J.S. Design of high-efficiency bidirectional DC-DC converter and high-precision efficiency measurement. IEEE Trans. Power Electron. 2010, 25, 650-658.

2. Yi, Z.; Dong, W.; Etemadi, A.H. A unified control and power management scheme for PV-battery-based hybrid microgrids for both grid-connected and islanded modes. IEEE Trans. Smart Grid. 2018, 9, 5975-5985. [CrossRef]

3. Rocabert, J.; Capo-Misut, R.; Munoz-Aguilar, R.S.; Candela, J.I.; Rodriguez, P. Control of Energy Storage System Integrating Electrochemical Batteries and Supercapacitors for Grid-Connected Applications. IEEE Trans. Ind. Appl. 2019, 55, 1853-1862. [CrossRef]

4. Liu, W.S.; Chen, J.F.; Liang, T.J.; Lin, R.L. Multicascoded sources for a high-efficiency fuel-cell hybrid power system in high-voltage application. IEEE Trans. Power Electron. 2011, 26, 931-9423. [CrossRef]

5. Konstantopoulos, G.C.; Alexandridis, A.T. Non-linear voltage regulator design for DC/DC boost converters used in photovoltaic applications: Analysis and experimental results. IET Renew. Power Gener. 2013, 7, 296-308. [CrossRef]

6. Wu, H.; Lu, Y.; Chen, L.; Xu, P.; Xiao, X.; Xing, Y. High step-up/step-down non-isolated BDC with built-in DC-transformer for energy storage systems. IET Power Electron. 2016, 9, 2571-2579. [CrossRef]

7. Lakshmi, M.; Hemamalini, S. Nonisolated high gain DC-DC converter for DC microgrids. IEEE Trans. Ind. Electron. 2018, 65, 1205-1212. [CrossRef] 
8. Li, W.; He, X. Review of nonisolated high-step-up DC/DC converters in photovoltaic grid-connected applications. IEEE Trans. Ind. Electron. 2011, 58, 1239-1249. [CrossRef]

9. Hart, D.W. Power Electronics, 1st ed.; McGraw-Hill Companies, Inc.: Madison, WI, USA; New York, NY, USA, 2011; pp. 211-220.

10. Marvi, M.; Fotowat-Ahmady, A. A fully ZVS critical conduction mode boost PFC. IEEE Trans. Power Electron. 2012, 58, 1958-1965. [CrossRef]

11. Xie, X.; Liu, C.P.; Poon, N.K.; Pong, M.H. A Novel High Frequency Current-Driven Synchronous Rectifier Applicable to Most Switching Topologies. IEEE Trans. Power Electron. 2001, 16, 635-648.

12. Yang, J.W.; Do, H.L. High-efficiency ZVS AC-DC LED driver using a Self-Driven synchronous rectifier. IEEE Trans. Circuits Syst. I Regul. Pap. 2014, 61, 2505-2512. [CrossRef]

13. Xinbo, R.; Liu, F. An improved ZVS PWM full-bridge converter with clamping diodes. In Proceedings of the 2004 IEEE 35th Annual Power Electronics Specialists Conference, Aachen, Germany, 20-25 June 2004; pp. 1476-1481.

14. Mousavi, A.; Das, P.; Moschopoulos, G. A comparative study of a new ZCS DC-DC full-bridge boost converter with a ZVS active-Clamp converter. IEEE Trans. Power Electron. 2012, 27, 1347-1358. [CrossRef]

15. Duarte, C.M.; Barbi, I. An improved family of ZVS-PWM active clamping DC-to-DC converters. IEEE Trans. Power Electron. 2002, 17, 684-691. [CrossRef]

16. Zhao, Y.; Li, W.; Deng, Y.; He, X. Analysis, Design, and Experimentation of an Isolated ZVT Boost Converter with Coupled Inductors. IEEE Trans. Power Electron. 2011, 26, 541-550. [CrossRef]

17. Moo, C.S.; Chen, Y.J.; Cheng, H.L.; Hsieh, Y.C. Twin-buck converter with zero-voltage transition. IEEE Trans. Ind. Electron. 2011, 58, 2366-2371. [CrossRef]

18. Hsieh, Y.C.; Chen, M.R.; Cheng, H.L. An interleaved flyback converter featured with zero-voltage transition. IEEE Trans. Power Electron. 2011, 26, 79-84. [CrossRef]

19. Hsieh, Y.C.; Hsueh, T.C.; Yen, H.C. An interleaved boost converter with zero-voltage transition. IEEE Trans. Power Electron. 2009, 24, 973-978. [CrossRef]

20. Gautam, D.C.; Bhat, A.K.S. A comparison of soft-switched DC-to-DC converters for electrolyzer application. IEEE Trans. Power Electron. 2013, 28, 54-63. [CrossRef] 